\title{
Response to Vinchon
}

\author{
Charles J. Hyman • David Ayoub • Marvin Miller
}

Received: 11 August 2010 /Accepted: 9 November 2010 /Published online: 21 December 2010

(C) Springer-Verlag 2010

\section{Dear Editor:}

Vinchon maintains that alleged abusers' "confessions" and/ or judicial decisions can confirm violent shaking as a cause of subdural hemorrhages in infants [1].

We suggest that it is time for physicians, especially medical journal reviewers, to disabuse themselves from accepting "alleged" perpetrator confessions and judicial outcomes as per se scientific confirmation of child abuse.

Certainly, some perpetrator confessions do accurately explain abusive acts causing subdural hemorrhage. However, it is common knowledge that there are "confessions" of those who maintain their innocence made to obtain a plea bargain to avoid the vagaries of a trial. In some cases, one parent will make a false admission in order to try and save his/her mate. Some, for multiple reasons, will confess to an act they did not commit. In reading and viewing interviews of alleged perpetrators, we find statements of resuscitative shaking or playful bouncing, or other playing similar to this being construed as the cause of a subdural hemorrhage [2]. This certainly should not be considered "violent" shaking". Whether shaking alone can cause subdural hemorrhage is still a zealously debated hypothesis [3, 4]. As medicine has proven through the ages, experience alone is not a substitute for the scientific method and does not prove a hypothesis [4].

We agree with Turkheimer that it is untenable to suggest that this particular scientific dispute should be decided in

\section{J. Hyman $(\square)$}

General and Forensic Pediatrics,

Redlands, CA 92373, USA

e-mail: cjhymanmd@keyway.net

D. Ayoub

Springfield, IL 62704, USA

\section{Miller}

Biomedical Engineering, Wright State University Boonshoft

School of Medicine,

Dayton, OH, USA courts. In our adversarial system, the presentation of scientific evidence is dependent on the constrictions imposed by the court, on the legal competency of the attorney, on the knowledge and communication skills of the expert, if they can afford one, and on the educational background and the capacity of the triers of fact to evaluate science. While judges, many of whom are learned legal minds, make decisions of cases brought before them, they do not have the scholarly standing in the biomedical community to determine the scientific validity of competing medical evidence $[5,6]$. Sadly, we have encountered judges who have abrogated judicial impartiality by failing to consider the possibilities of competing medical science and advocating for the omniscience of the state's child abuse experts.

The natural course of scientific evolution has resolved many medical conflicts separating scientifically valid arguments from opinion and speculation. Until that time, confessional data and judicial decision must be considered with caution and cannot be taken as per se determinants of child abuse.

\section{References}

1. Vinchon M (2010) Reply to Gardner. Child Nerv Syst 26(11):1485

2. Leestma JE (2006) "Shaken baby syndrome": do confessions by alleged perpetrators validate the concept? J Am Phys Surg 11:14-16

3. Duhaime AC, Gennarelli TA, Thibault LE et al (1987) The shaken baby syndrome. A clinical, pathological, and biomechanical study. J Neurosurg 66:409-415

4. Dias MS. (2010) The case for shaking. In: Jenny C. Child abuse and neglect: diagnosis, treatment and evidence. Saunders; Har/Psc edition, Philadelphia

5. Tuerkheimer D (2009) The next innocence project: Shaken baby syndrome and the criminal courts. Wash Univ Law Rev 87(1):1-58

6. Tuerkheimer D (2010) Criminal justice at a crossroads: Sciencedependent prosecution and the problem of epistemic contingency. Alabama Law Review 62(in press). Available at SSRN: http://ssm. com/abstract=1579394 (March 27) 